\title{
Global temperature estimates in the troposphere and stratosphere: a validation study of COSMIC/FORMOSAT-3 measurements
}

\author{
P. Kishore ${ }^{1}$, S. P. Namboothiri ${ }^{2}$, J. H. Jiang ${ }^{3}$, V. Sivakumar ${ }^{4,5}$, and K. Igarashi ${ }^{2}$ \\ ${ }^{1}$ Dept. of Physics and Atmospheric Science, Dalhousie University, Halifax, Canada \\ ${ }^{2}$ National Institute of Information and Communications Technology, Tokyo, Japan \\ ${ }^{3}$ Jet Propulsion Laboratory, Pasadena, CA, USA \\ ${ }^{4}$ National Laser Centre, CSIR, Pretoria, South Africa \\ ${ }^{5}$ Department of Geography, Geoinformatics and Meteorology, University of Pretoria, South Africa
}

Received: 13 November 2007 - Published in Atmos. Chem. Phys. Discuss.: 6 May 2008

Revised: 12 September 2008 - Accepted: 8 December 2008 - Published: 4 February 2009

\begin{abstract}
This paper mainly focuses on the validation of temperature estimates derived with the newly launched Constellation Observing System for Meteorology Ionosphere and Climate (COSMIC)/Formosa Satellite 3 (FORMOSAT3) system. The analysis is based on the radio occultation (RO) data samples collected during the first year observation from April 2006 to April 2007. For the validation, we have used the operational stratospheric analyses including the National Centers for Environmental Prediction - Reanalysis (NCEP), the Japanese 25-year Reanalysis (JRA-25), and the United Kingdom Met Office (MetO) data sets. Comparisons done in different formats reveal good agreement between the COSMIC and reanalysis outputs. Spatially, the largest deviations are noted in the polar latitudes, and heightwise, the tropical tropopause region noted the maximum differences $(2-4 \mathrm{~K})$. We found that among the three reanalysis data sets the NCEP data sets have the best resemblance with the COSMIC measurements.
\end{abstract}

\section{Introduction}

Temperatures are important in many aspects of atmospheric research and many studies have investigated the accuracy of derived temperature profiles (e.g. Hertzog et al., 2003; Pommerau et al., 2002; Knudsen et al., 2002). Knowledge of the upper tropospheric and lower stratospheric temperatures is important for understanding the structure and dynamics of

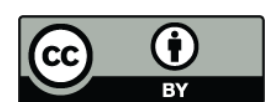

Correspondence to: P. Kishore (kishore1818@gmail.com) the region, and is related to the issues connected to global climate change and the stratosphere-troposphere exchanges (Holton et al., 1995; Baray et al., 1998; Burris et al., 1998; Steinbrecht et al., 1998). A wide variety of observational techniques have been used to measure temperature in the troposphere and lower stratosphere and their variations in time and space. These techniques include balloon soundings (e.g. Kitamura and Hirota, 1989; Tsuda et al., 1991), rocketsonde measurements (e.g. Dewan et al., 1984; Hamilton, 1991; Eckermann et al., 1995), and lidar studies (e.g. Wilson et al., 1991; Hauchecorne and Chanin, 1980; Chanin and Hauchecorne, 1991; Whiteway and Carswell, 1994; LeBlanc et al., 1998; Sivakumar et al., 2003), etc. Most of these observations are mainly over land areas of the Northern Hemisphere (NH) and the period of observations has been limited. This raises the problem of insufficient data for establishing climatology for a global scale, despite the good results from many of the ground-based and space-borne instruments (Steiner and Kirchengast, 2000). Recently Global Positioning Systems (GPS) Radio occultation (RO) observations started offering several important and unique features complementary to other methods of observing the Earth's atmosphere. The GPS-RO technique has the advantages of global coverage, high accuracy, high vertical resolution (less than $1 \mathrm{~km}$ ), long-term stability, self-calibration and capability to operate in all-weather conditions (Kursinski et al., 1997; Wickert et al., 2001; Hajj et al., 2002).

The GPS-RO technique has been very useful in collecting the global high-resolution data sets of atmospheric refractivity, temperature, pressure, and water vapour profiles. Using the GPS/MET data, initial investigations of the temperature variations in the tropical tropopause region were

Published by Copernicus Publications on behalf of the European Geosciences Union. 


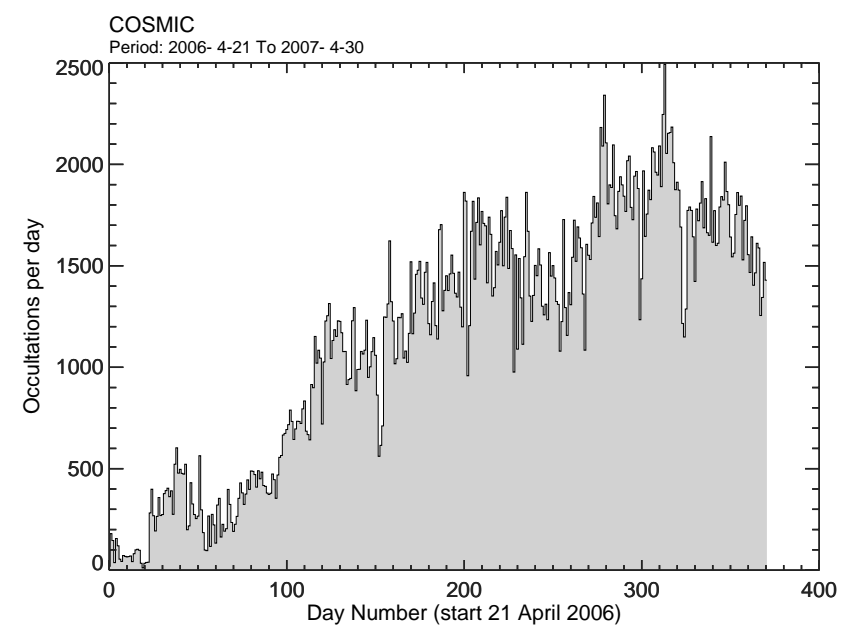

Fig. 1. Histogram of number of occultations (per day) for the period from 21 April 2006 to 30 April 2007.

performed by Nishida et al. (2000) and Randel et al. (2003). The CHAMP and SAC-C profiles occurring within $30 \mathrm{~min}$ and $200 \mathrm{~km}$ are compared and agreed to better than $0.86 \mathrm{~K}$ and to within $0.1 \mathrm{~K}$ in the mean between 5 and $15 \mathrm{~km}$ altitude, after removing the expected variability of the atmosphere (Hajj et al., 2004). Wang et al. (2004) compared more than 100 temperature profiles collected using the Michelson Interferometer for Passive Atmospheric Sounding (MIPAS) and the CHAMP during 14 days in September/October 2002. They found good agreement in the upper troposphere and lower stratosphere.

The US/Taiwanese Constellation Observing System for Meteorology Ionosphere and Climate (COSMIC/FORMOSAT-3) satellite was successfully launched on 15 April 2006. This mission is expected to bring the innovative use of GPS RO data for atmospheric and ionospheric research, for improving global weather forecasts and climate change related studies. A distinctive feature of the COSMIC mission, compared to previous RO missions, is tracking both setting and rising neutral atmospheric occultations in the lower troposphere in an open-loop (OL) mode (Schreiner et al., 2007). This is very important for detecting the moisture variation in the lower troposphere, which is very useful for weather prediction and climate analysis.

In this paper, we use the operational stratospheric analyses data sets for the validation of upper troposphere and lower stratosphere temperature profiles obtained by the COSMIC system. These operational data sets include those implemented at the National Centers for Environmental Prediction - Reanalysis (NCEP-Reanalysis), the Japanese 25-year Reanalysis (JRA-25), and the UK Met Office (MetO). In the next section we provide some details of the data analysis. Results obtained from the present analysis in terms of comparison between COSMIC satellite and reanalysis are described in Sect. 3. We describe the global temperature behaviour noted by each measurement and their differences of temperatures with respect to the COSMIC, for summer and winter seasons for particular pressure levels. Comparison of the latitudinal temperature has been carried out for different pressure levels. Finally, the conclusions of the present analysis are summarized in Sect. 4.

\section{Data analysis}

\subsection{COSMIC}

GPS-RO measurements are active limb sounding measurements of the Earth's atmosphere. This technique has emerged as a promising approach for global atmospheric measurements. Under the assumption of geometric optics and local spherical symmetry of the atmosphere, the phase delay measurements can be directly inverted to yield the index of refraction profile with vertical resolution (interpolated) that varies from about $50 \mathrm{~m}$ in the lower troposphere to about $200-300 \mathrm{~m}$ in the lower stratosphere. Note that the original height resolution varies from about $500 \mathrm{~m}$ in the lower troposphere to about $1 \mathrm{~km}$ in the lower stratosphere. As mentioned previously, the COSMIC satellite system (Rocken et al., 2000), a constellation of six LEO micro-satellites, was put into orbit on 15 April, 2006. Since 21 April 2006, GPSRO technique has been providing accurate and high vertical resolution global data sets of atmospheric parameters. In the present study, we used the COSMIC RO data collected during the one year period from 21 April 2006 to 30 April 2007.

Figure 1 shows the histogram of number of occultations (per day) obtained by COSMIC soundings that cover the period from 21 April 2006 to 30 April 2007. The total number of occultations is 425797 during this period of observation. During the initial months the daily occultations were less than 400, and it has increased enormously, from August 2006 , to about 1400-1600 soundings within the height interval $0-40 \mathrm{~km}$. The maximum number of occultations (per day) is observed on 4 March 2007 and is 2493.

\subsection{NCEP reanalysis (NCEP)}

The reanalysis data set was created through the cooperative efforts of the National Centers for Environmental Prediction (NCEP) and National Center for Atmospheric Research (NCAR) to produce relatively high-resolution global analyses of atmospheric fields over a long time period (Kalnay et al., 1996; Kistler et al., 2001). Data from many different sources (including rawinsondes, balloons, aircrafts, ships, surface stations and satellites) were put through a quality check, fed into an assimilation model that includes parameterizations for all major physical processes, and finally examined again for self consistency. The data sets contain daily averages (with 4 times a day at 00:00, 06:00, 12:00 


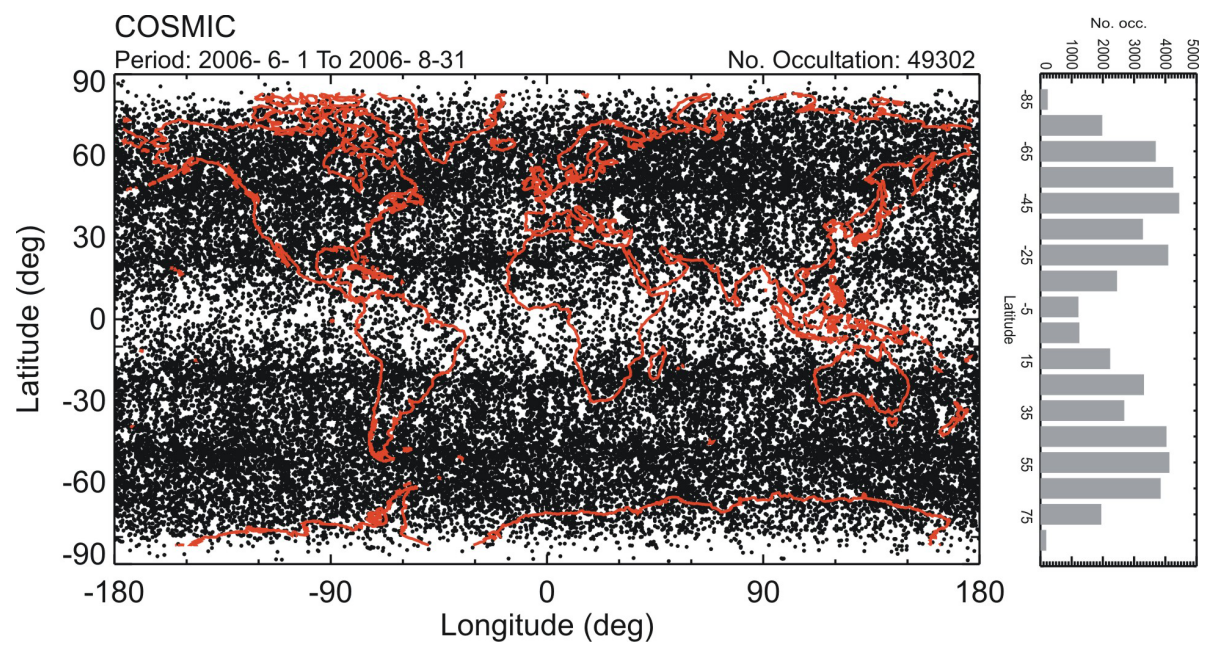

Fig. 2. Global coverage of COSMIC occultations for the Northern Hemisphere summer (1 June 2006-31 August 2006). Histogram of total number of occultations occurred in every 10 degree latitude range is shown in the right panel.

and 18:00 UT) of geopotential height, wind, and temperature on 17 pressure levels above the surface (from $1000 \mathrm{hPa}$ to $10 \mathrm{hPa}$ ) with spatial resolution of $2.5 \times 2.5$ (degrees), with a resulting horizontal grid of $144 \times 73$ points. This translates the horizontal resolution of the data set equivalent to $\sim 300 \mathrm{~km}$.

\subsection{JRA-25 reanalysis (JRA-25)}

The Japanese 25-year reanalysis (JRA-25) is an up-to-date data set produced by the Japan Meteorological Agency (JMA) and the Central Research Institute of Electrical Power Industry (CRIEPI). The main components of the system are a spectral forecast model, various quality control (QC) processes, a three-dimensional variational (3D-Var) data assimilation process, and a land surface model. JRA-25 reanalysis is a basic meteorological grid point data set with uniform resolution of $\sim 300 \mathrm{~km}$ in the horizontal and from the surface to about $50 \mathrm{~km}$ in the vertical. The output contains over $200 \mathrm{me}-$ teorological parameters globally with 23 vertical levels from $1000 \mathrm{hPa}$ to $0.4 \mathrm{hPa}$ and the resolution of $2.5 \times 2.5$ degree intervals in longitude/latitude and for four times a day (00:00, 06:00, 12:00, and 18:00 UT). A 3D-Var data assimilation system is adopted for assimilating various kinds of satellite data effectively (Onogi et al., 2005, 2007).

\subsection{UK Met observations (MetO)}

A data assimilation system has been developed at the UK Meteorological Office (UKMO) to analyze the various observations available in the troposphere and stratosphere. The data assimilation system is based on the analysis correction scheme used at the UKMO for operational weather forecasting (Swinbank and O'Neill, 1994). The analysis consists of temperatures, wind components, and geopotential heights on a global grid of resolution $2.5 \times 3.75$ degree (latitude/longitude) with 22 vertical pressure levels from 1000 to $0.32 \mathrm{hPa}$ corresponds to the altitude range of $0-55 \mathrm{~km}$. The data output is given for 12:00 UT. The aim of the assimilation project is to provide a self-consistent sequence of three-dimensional grid point analyses of the atmosphere, up to the lower mesosphere. The sequence of synoptic analyses is constructed from a heterogeneous mixture of observational data. Since November 2000, the MetO stratospheric analyses have been produced using a new three-dimensional variational data assimilation system (Lorenc et al., 2000).

\section{Results and discussion}

In this section we focus on comparison of COSMIC temperature profiles with the NCEP, MetO, and JRA-25 reanalysis data sets. Prior to the comparisons with reanalysis data sets, for each RO profile a coinciding profile was extracted from the reanalysis data, i.e. by spatially interpolating the reanalysis data of nearest coordinates (time and locations) to the locations of the RO soundings.

In order to note the global coverage of COSMIC RO, an example of the global occultations for the NH summer season is shown in Fig. 2, where the total number of occultations is 49302. Here the NH summer season represents the period from June to August. In Fig. 2 (right panel) we also show the histogram of number of occultation occurred at every 10 degree latitude range. It is evident in the figure that the data coverage is very good for the latitude sector $80^{\circ} \mathrm{S}-$ $80^{\circ} \mathrm{N}$. The coverage in the equatorial region is lesser than the midlatitude regions. The near Polar regions $\left(80^{\circ}-90^{\circ}\right)$ are marked with very low coverage. The summer occultation coverage at the midlatitudes of the $\mathrm{NH}$ and $\mathrm{SH}$ (Southern Hemisphere) is more than 3000 occultations, whereas the 

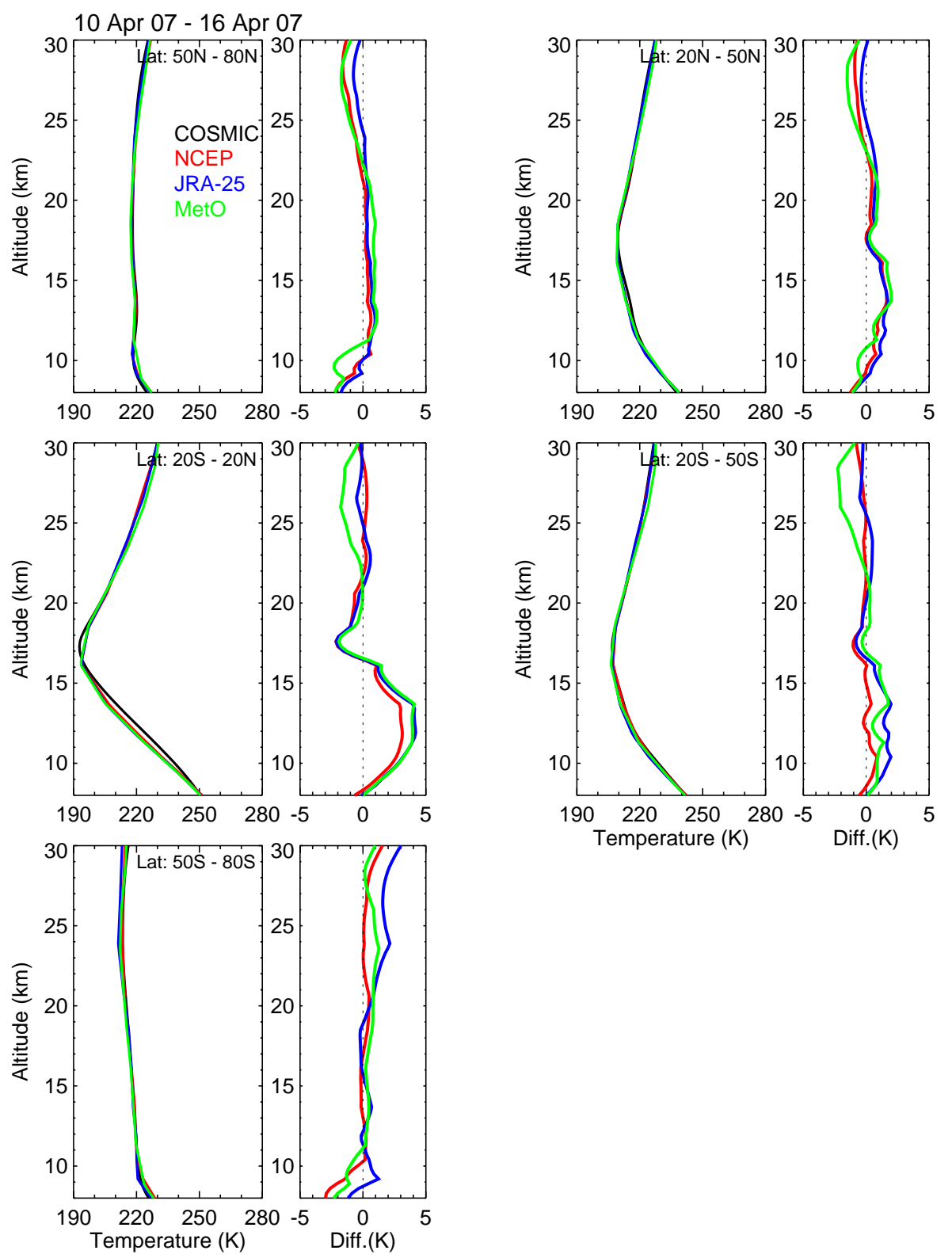

Fig. 3. Height profiles of the COSMIC and reanalysis temperatures derived for various latitude bands and for the period 10 April $2007-16$ April 2007. In each right sub-panel the difference in temperature with respect to COSMIC measurements and reanalysis values is plotted.

equatorial region shows a comparatively smaller number (little more than 1000). We have examined the winter coverage and found that the number of occultation is more than the summer occultations.

\subsection{Mean temperature}

First, we compare the mean temperature profiles retrieved from COSMIC RO measurements with reanalysis data sets. Figure 3 shows the height profiles $(8-30 \mathrm{~km})$ of zonal-mean temperatures for five different latitude bands during the one week period 10 April 2007 to 16 April 2007. Here we present the data sets of COSMIC, NCEP, JRA-25, and MetO. To determine the mean temperatures, all the available longitudinal data at individual height are sorted into latitude bins of a specified width. The selected latitudinal sectors cover the high-, mid- and low-latitude regions in both Northern and Southern Hemispheres, and they are $50^{\circ} \mathrm{N}-80^{\circ} \mathrm{N}$, $20^{\circ} \mathrm{N}-50^{\circ} \mathrm{N}, 20^{\circ} \mathrm{N}-20^{\circ} \mathrm{S}, 20^{\circ} \mathrm{S}-50^{\circ} \mathrm{S}$, and $50^{\circ} \mathrm{S}-80^{\circ} \mathrm{S}$. In Fig. 3, in addition to the mean temperature profiles (left subpanel) we also show the differences (right sub-panel) with respect to the COSMIC temperatures. In general, comparison of the COSMIC and reanalysis temperatures reveals good agreement. For altitudes below $8 \mathrm{~km}$ we found some 

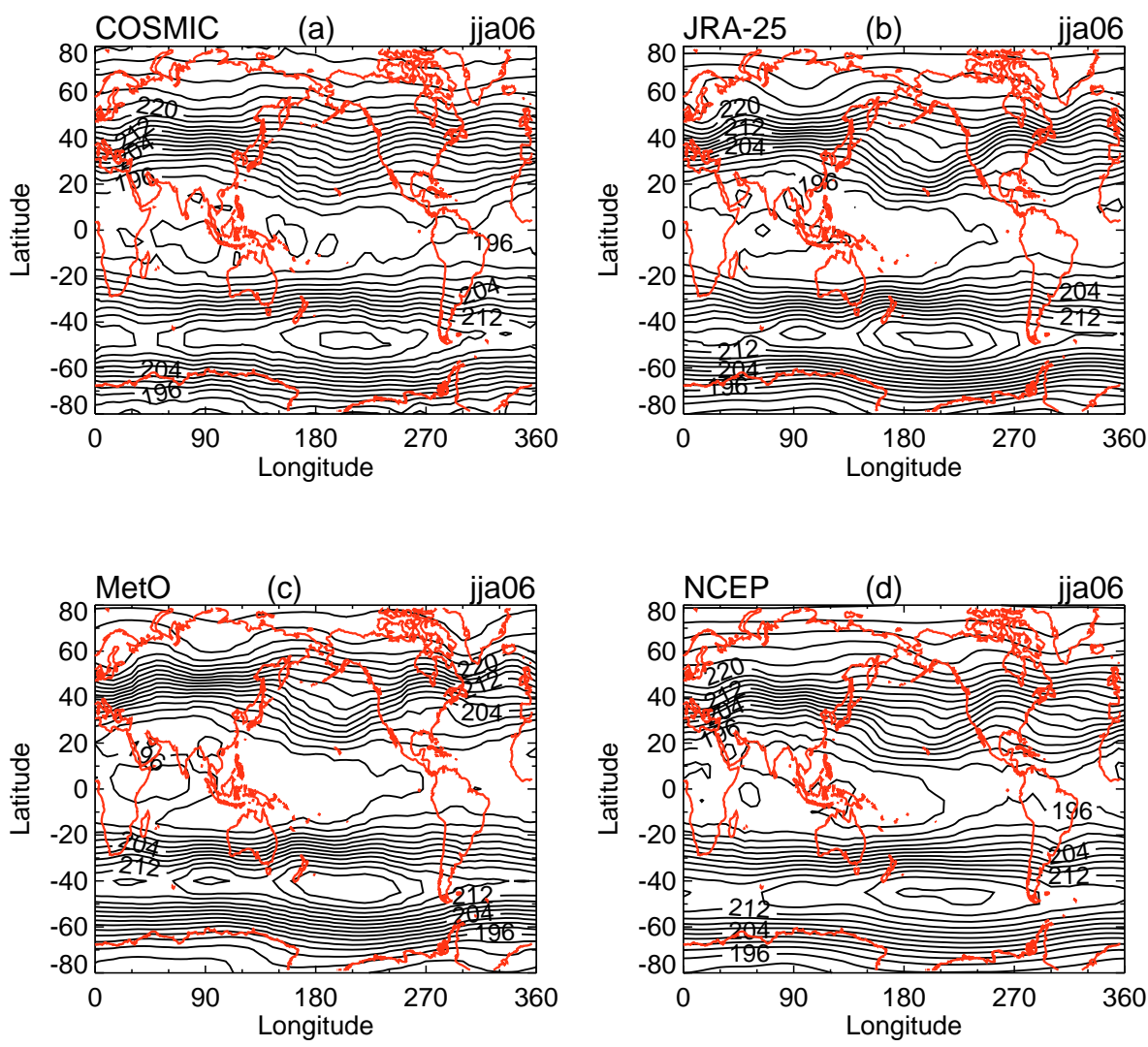

Fig. 4. Mean global temperatures at $100 \mathrm{hPa}$ by (a) COSMIC, (b) JRA-25, (c) MetO and (d) NCEP data sets during Northern Hemisphere summer (June-August, 2006). The contour interval is $2 \mathrm{~K}$.

differences, which are due to interference from water vapor existence and thus the temperature retrieval is erroneous at those heights. Also the correction due to ionospheric residuals will create issues at altitudes above $45 \mathrm{~km}$, and sometimes even from $35 \mathrm{~km}$ and above (Rocken et al., 1997; Syndergaard 2000). Hence we have restricted our comparisons to the height range between 8 and $30 \mathrm{~km}$. The mean differences between COSMIC and reanalysis at most of the individual heights vary between $1-2 \mathrm{~K}$, and the mean difference averaged over the height region $8-30 \mathrm{~km}$ is noted as values between -0.75 and $0.9 \mathrm{~K}$ for all the five latitude bands. Larger deviations are seen in the equatorial $\left(20^{\circ} \mathrm{S}-\right.$ $20^{\circ} \mathrm{N}$ ) troposphere region, where the data sets exhibit differences of about $2.5-4 \mathrm{~K}$. It is not clear whether these differences are due to larger uncertainties in the COSMIC data or based on the analyses. The enhanced gravity wave activity near the equator could also introduce larger differences. Using the CHAMP data, it has been shown that the increase of the tropical bias and root mean square deviation is related to gravity waves (Marquardt et al., 2002). Comparing the reanalyses, the NCEP data show the least difference than all other data sets. The figure demonstrates positive differences in the troposphere and negative differences in the stratospheric heights indicating warmer and colder tempera- tures by COSMIC. The comparatively larger COSMIC temperatures in the upper troposphere than in the lower troposphere is due to the moist adiabatic lapse rate decreasing with the increasing temperatures and the lower stratosphere cooling is due to increased longwave emission is to a large degree offset by increased absorption of upwelling longwave radiation from the troposphere (Ringer and Healy, 2008). Schmidt et al. (2004) compared the CHAMP temperature data with nearby radiosonde observations and they found that temperature bias is less than $0.5 \mathrm{~K}$ in the upper troposphere and lower stratosphere region. The cold bias above $20 \mathrm{~km}$ is related to the bending angle smoothing and the interpolation procedure for the downward integration of the refractivity profile. Recently, Kishore et al. (2006) made statistical estimates of the bias between the CHAMP, SAC-C, and radiosonde temperature measurements obtained for different latitude sectors during the period from March 2002 to December 2003. Their results demonstrated that the mean bias in the troposphere is less than $0.7 \mathrm{~K}$ and it is comparatively larger in the stratosphere (between 0.9-1.5 K). In another analysis Borsche et al. (2007) compared the CHAMP temperatures with ECMWF and NCEP reanalyses data sets for the tropics $\left(15^{\circ} \mathrm{S}-15^{\circ} \mathrm{N}\right)$. In the case of ECMWF they reported excellent overall agreement except near the tropopause height, 

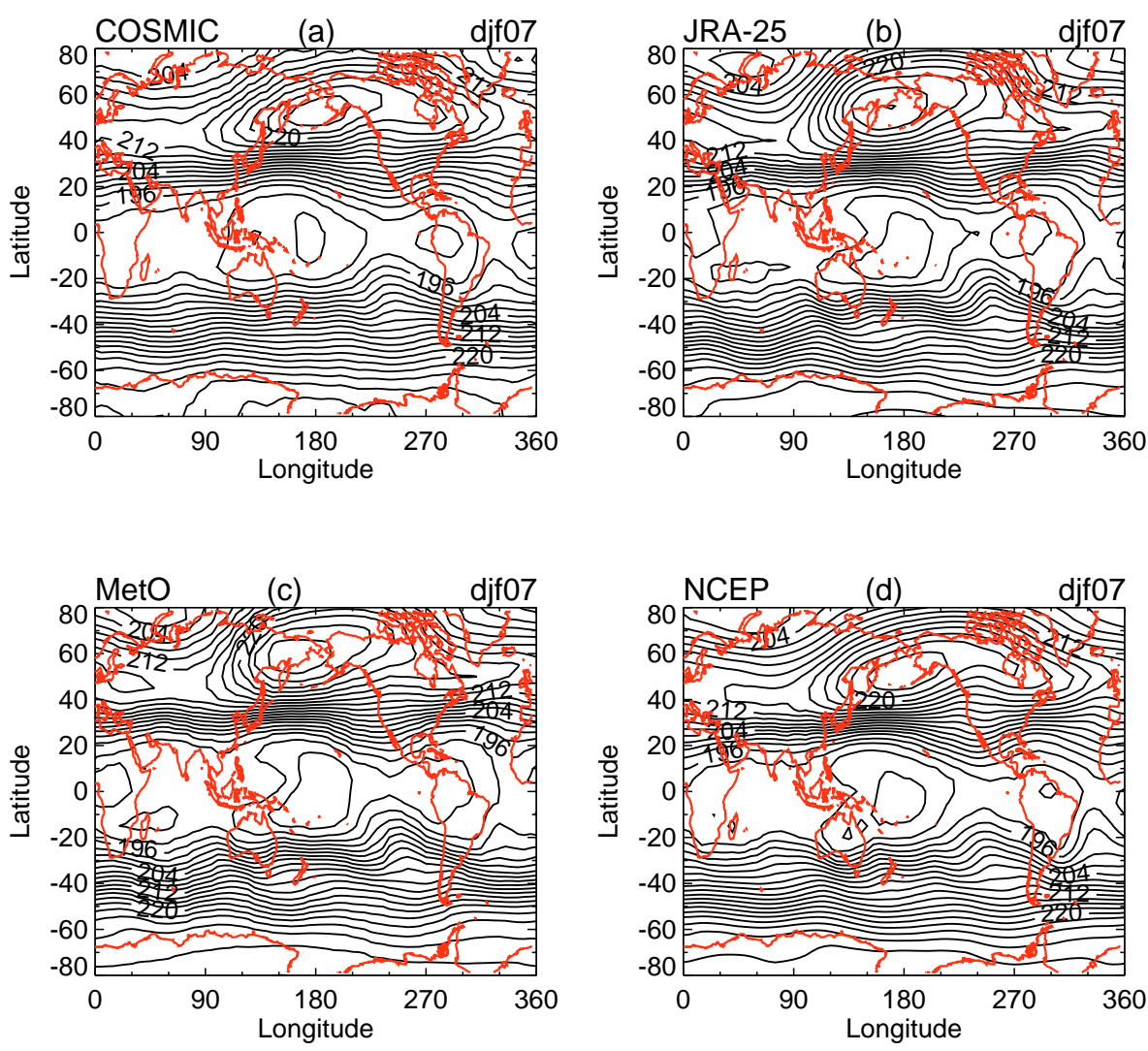

Fig. 5. Same as Fig. 4, but for the Northern Hemisphere winter (December 2006, January, February 2007).

where systematic differences generally amount to $-1 \mathrm{~K}$ to $-2 \mathrm{~K}$. However, the NCEP showed larger deviations of about $+2 \mathrm{~K}$ to $+4 \mathrm{~K}$ for the tropopause.

\subsection{Longitudinal - latitudinal temperature variations}

Here we would like to describe the spatial structure of the temperatures derived from COSMIC RO measurements and comparison with the reanalysis data sets JRA-25, MetO, and NCEP during the NH summer (June, July, and August) of 2006. Figure $4 \mathrm{a}-\mathrm{d}$ represents the temperature contours (at $100 \mathrm{hPa}$ ) derived by the COSMIC, JRA-25, MetO and NCEP data sets, respectively. The data used in this study have been obtained at standard pressure levels, and interpolated onto a $5^{\circ} \times 5^{\circ}$ longitude-latitude grid. For COSMIC measurements, we note that for each $5^{\circ}$ bin there are $10-15$ profiles in the tropical region $\left(20^{\circ} \mathrm{S}-20^{\circ} \mathrm{N}\right) .18-25$ profiles in the midlatitudes and 7-12 profiles in the high latitudes. Describing the features, it can be seen that the temperature structure of the COSMIC and reanalysis looks similar. The northern Polar region temperature is close to $228 \mathrm{~K}\left(-45^{\circ} \mathrm{C}\right)$ whereas the temperature at southern Polar region is about $28 \mathrm{~K}$ lower (Note that the northern summer corresponds to the southern winter). In southern midlatitudes $\left(35^{\circ} \mathrm{S}-45^{\circ} \mathrm{S}\right)$ the maximum temperatures is about $216 \mathrm{~K}$ for COSMIC and reanal- ysis data sets. For all the data sets the tropical minimum temperature is about $194 \mathrm{~K}\left(-79^{\circ} \mathrm{C}\right)$. However, note that the extent of the $194 \mathrm{~K}$ contour is far larger in the NCEP than in the COSMIC data. Also the locations differ with the NCEP spanning from the northwest Indian Ocean down to a region near the South Pacific Convergence Zone (SPCZ) whereas the COSMIC $194 \mathrm{~K}$ contour is more broken into smaller spatial regions with the biggest one spanning the equatorial Indian Ocean. The tropical tropopause is expected to occur at about $16 \mathrm{~km}$. Hoinka (1998) reported that for all latitudes the temperature at $100 \mathrm{hPa}$ level provides a first estimate of tropopause temperature.

The global temperature structure generated by the COSMIC and reanalysis values for the northern winter (December 2006, January and February 2007) at $100 \mathrm{hPa}$ pressure level is shown in Fig. 5a-d. Looking at the temperature pattern at the Polar regions we can see that the Arctic temperature is about $206 \mathrm{~K}$, whereas it is close to $228 \mathrm{~K}$ in the Antarctic region. In the tropics, temperature reaches to about $190 \mathrm{~K}$, which is observed in the western Pacific and is similar in COSMIC data and in the reanalysis data sets. Newell et al. (1972) had reported that the largest region of lowest temperatures (colder than $-82.5^{\circ} \mathrm{C}$ in the seasonal mean) at $100 \mathrm{hPa}$ occurs over the western Pacific Ocean in winter. Secondary regions of limited extent appear over 
Table 1. The temperature bias between the COSMIC and reanalysis data sets calculated for different latitude sectors during summer and winter seasons and at $100 \mathrm{hPa}$.

\begin{tabular}{crrrrrr}
\hline Latitude & COSMIC-NCEP (K) & $\begin{array}{c}\text { Summer }(100 \mathrm{hPa}) \\
\text { COSMIC-MetO }(\mathrm{K})\end{array}$ & COSMIC-JRA25 (K) & COSMIC-NCEP (K) & $\begin{array}{c}\text { Winter }(100 \mathrm{hPa}) \\
\text { COSMIC-MetO (K) }\end{array}$ & COSMIC-JRA25 (K) \\
\hline $50^{\circ} \mathrm{N}-80^{\circ} \mathrm{N}$ & $-0.043 \pm 0.69$ & $0.993 \pm 0.78$ & $0.346 \pm 0.46$ & $-0.066 \pm 0.43$ & $-0.981 \pm 1.03$ \\
$20^{\circ} \mathrm{N}-50^{\circ} \mathrm{N}$ & $-0.184 \pm 0.45$ & $0.752 \pm 0.76$ & $0.053 \pm 0.74$ & $-0.324 \pm 0.78$ & $-0.187 \pm 0.56$ \\
$20^{\circ} \mathrm{N}-20^{\circ} \mathrm{S}$ & $0.296 \pm 0.78$ & $-0.531 \pm 0.89$ & $-0.602 \pm 0.98$ & $-0.245 \pm 0.77$ & $0.614 \pm 0.88$ & $-0.779 \pm 1.23$ \\
$20^{\circ} \mathrm{S}-50^{\circ} \mathrm{S}$ & $-0.478 \pm 0.88$ & $0.261 \pm 0.55$ & $-0.401 \pm 0.67$ & $-0.332 \pm 0.72$ & $0.350 \pm 0.78$ & $0.140 \pm 0.49$ \\
$50^{\circ} \mathrm{S}-80^{\circ} \mathrm{S}$ & $-0.854 \pm 1.23$ & $1.921 \pm 2.01$ & $1.381 \pm 1.44$ & $-1.078 \pm 1.56$ & $-0.602 \pm 1.49$ \\
\hline
\end{tabular}

Table 2. Temperature bias between the COSMIC and reanalysis data sets calculated for different latitude sectors during summer and winter seasons and at $50 \mathrm{hPa}$.

\begin{tabular}{crrrrrr}
\hline Latitude & COSMIC-NCEP (K) & $\begin{array}{c}\text { Summer }(50 \mathrm{hPa}) \\
\text { COSMIC-MetO }(\mathrm{K})\end{array}$ & COSMIC-JRA25 (K) & COSMIC-NCEP (K) & $\begin{array}{c}\text { Winter (50 hPa) } \\
\text { COSMIC-MetO (K) }\end{array}$ & COSMIC-JRA25 (K) \\
\hline $50^{\circ} \mathrm{N}-80^{\circ} \mathrm{N}$ & $-0.672 \pm 1.29$ & $0.562 \pm 0.89$ & $0.391 \pm 0.66$ & $-1.094 \pm 2.13$ & $-1.594 \pm 2.43$ \\
$20^{\circ} \mathrm{N}-50^{\circ} \mathrm{N}$ & $-0.196 \pm 0.58$ & $-0.346 \pm 0.75$ & $-0.246 \pm 0.59$ & $-0.052 \pm 0.89$ & $-0.075 \pm 1.16$ \\
$20^{\circ} \mathrm{N}-20^{\circ} \mathrm{S}$ & $-0.227 \pm 0.65$ & $-0.213 \pm 0.79$ & $-0.313 \pm 0.88$ & $0.066 \pm 0.99$ & $0.087 \pm 0.45$ & $0.093 \pm 0.45$ \\
$20^{\circ} \mathrm{S}-50^{\circ} \mathrm{S}$ & $-0.162 \pm 0.66$ & $-0.780 \pm 1.05$ & $-0.880 \pm 1.47$ & $-0.164 \pm 0.82$ & $-0.145 \pm 0.74$ \\
$50^{\circ} \mathrm{S}-80^{\circ} \mathrm{S}$ & $-0.279 \pm 0.73$ & $1.252 \pm 1.62$ & $1.452 \pm 1.78$ & $0.609 \pm 1.19$ & $1.775 \pm 2.09$ \\
\hline
\end{tabular}

Northern South America and Africa. Newell and GouldStewart (1981) presumed a significant water vapor transport from the troposphere into the stratosphere in these regions and it is most active in the west Pacific in winter and moves to the monsoon region for the NH summer. Both COSMIC and reanalysis noticed the $\mathrm{NH}$ maximum temperatures of $\sim 224 \mathrm{~K}$ at $50^{\circ} \mathrm{N}$. Concluding the summer and winter temperature features observed in the contours, it can be stated that the structure generated by the COSMIC and reanalysis has encouraging similarity, which will be further established with the temperature differences explained below.

The longitude-latitude structure of the temperature differences between COSMIC and reanalysis data set at $100 \mathrm{hPa}$ level is shown in Figs. 6 and 7, for summer and winter, respectively. In each figure, (a) corresponds to COSMICJRA-25, (b) denotes COSMIC-MetO, and (c) represents the COSMIC-NCEP data sets. Examining the Fig. 6 we can see that the difference between the COSMIC and other measurements is not very large. Maximum deviation of $2 \mathrm{~K}$ is observed in limited areas. Such deviations are generally observed in the high latitudes in the SH. It is evident that the COSMIC and the NCEP reanalysis values match better than the other two pairs. Note that the solid line denotes warmer COSMIC temperature and dotted line denotes colder COSMIC temperature. For a large latitude/longitude sector, the summer temperature difference is about $0.75-1.25 \mathrm{~K}$. Schmidt et al. (2004) compared the CHAMP with ECMWF analyses data sets in the troposphere and lower stratosphere for the period of May 2001 and September 2002 and they reported that the average bias in the upper troposphere and lower stratosphere $(250-30 \mathrm{hPa})$ is less than $1.5 \mathrm{~K}$. Gobiet et al. (2005) made a seasonal latitude-height temperature structure of CHAMP and compared with ECMWF operational analysis using 2.5 year data sets. They noted mean temperature cold biases of $-2.5 \mathrm{~K}$ (maximum) and warm biases up to $+3.5 \mathrm{~K}$ in the Austral polar vortex region.

Figure 7 shows the global distribution of the winter temperature differences between COSMIC and reanalysis. It illustrates that in the $\mathrm{NH}$ the largest differences occur with cold biases of $-4.5 \mathrm{~K}$ with MetO and JRA-25. However, the NCEP data show differences of only about -1.5 to $-2.5 \mathrm{~K}$ over the Antarctic region. The corresponding differences observed in the $\mathrm{SH}$ are smaller, typically ranging between -1.5 and $-2.5 \mathrm{~K}$ for all the analyses. The mean differences are relatively small between $30^{\circ} \mathrm{S}$ and $30^{\circ} \mathrm{N}$ at about $1.0-1.25 \mathrm{~K}$. Figure 7 further indicates that the COSMIC temperature observed to be warmer in the latitude range of $30^{\circ} \mathrm{S}-30^{\circ} \mathrm{N}$ and colder in the northern and southern polar regions. In the beginning of winter the polar vortex edge was located at the northern high latitudes especially above Europe, but moved significantly as the warming progressed and it might be one of the causes for increased temperature differences. From the summer and winter patterns shown in Figs. 6 and 7, it can be seen that the differences observed in $\mathrm{NH}$ winter (SH summer) are significantly larger than the NH summer ( $\mathrm{SH}$ winter) and this reflects the SH winter circulation in the upper troposphere and lower stratosphere is less disturbed than in the $\mathrm{NH}$ winter. We note that the maxima of the seasonal mean 

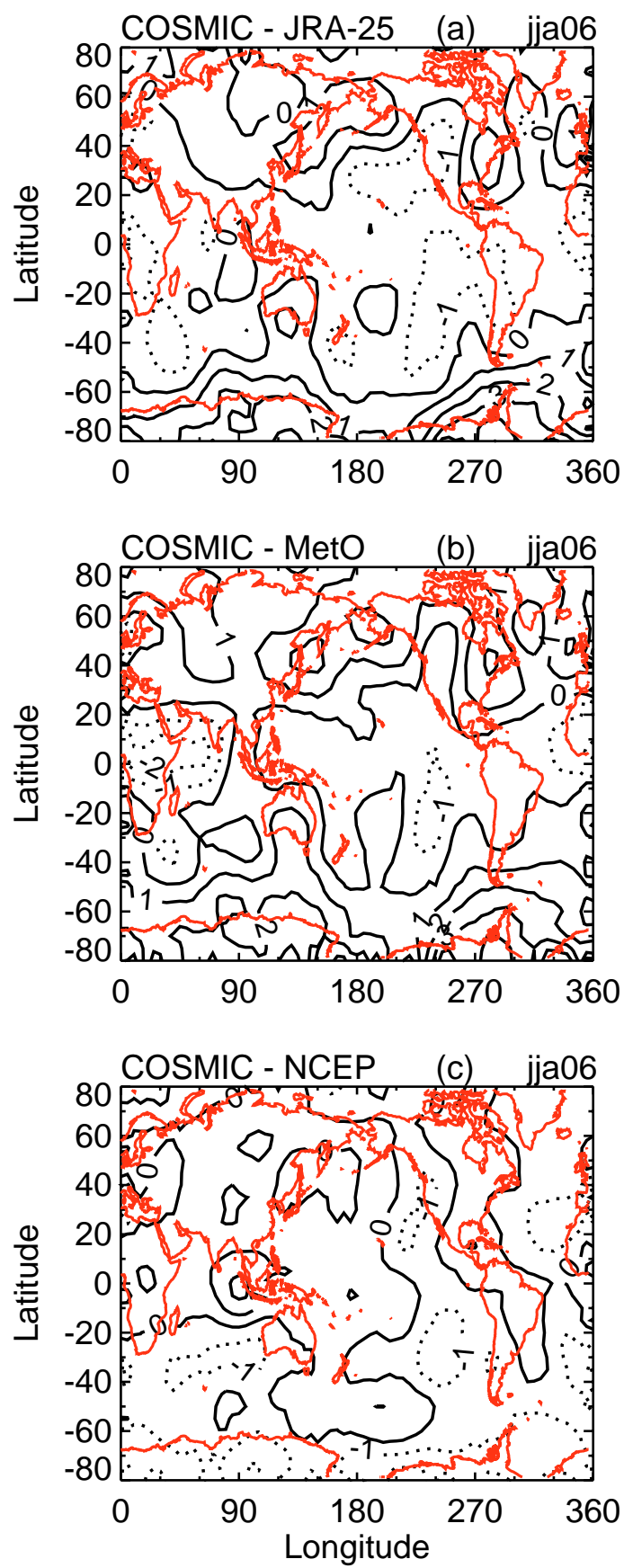

Fig. 6. Global zonal mean temperature (at $100 \mathrm{hPa}$ ) differences (in Kelvin) between (a) COSMIC-JRA-25, (b) COSMIC-MetO, and (c) COSMIC-NCEP during Northern Hemisphere summer (JuneAugust 2006). The contour interval is $1 \mathrm{~K}$.

differences between COSMIC and reanalysis at $100 \mathrm{hPa}$ is larger during $\mathrm{NH}$ winter than summer season. The MIPAS and CHAMP comparison studies demonstrated a maximum bias of $\sim 1-1.5 \mathrm{~K}$ at $30 \mathrm{~km}$ (Wang et al., 2004). Further, using the MIPAS and SAC-C data sets, Jiang et al. (2004) estimated the mean differences for 5-30 km and for two different seasons. Their estimate was less than $\sim 2 \mathrm{~K}$.
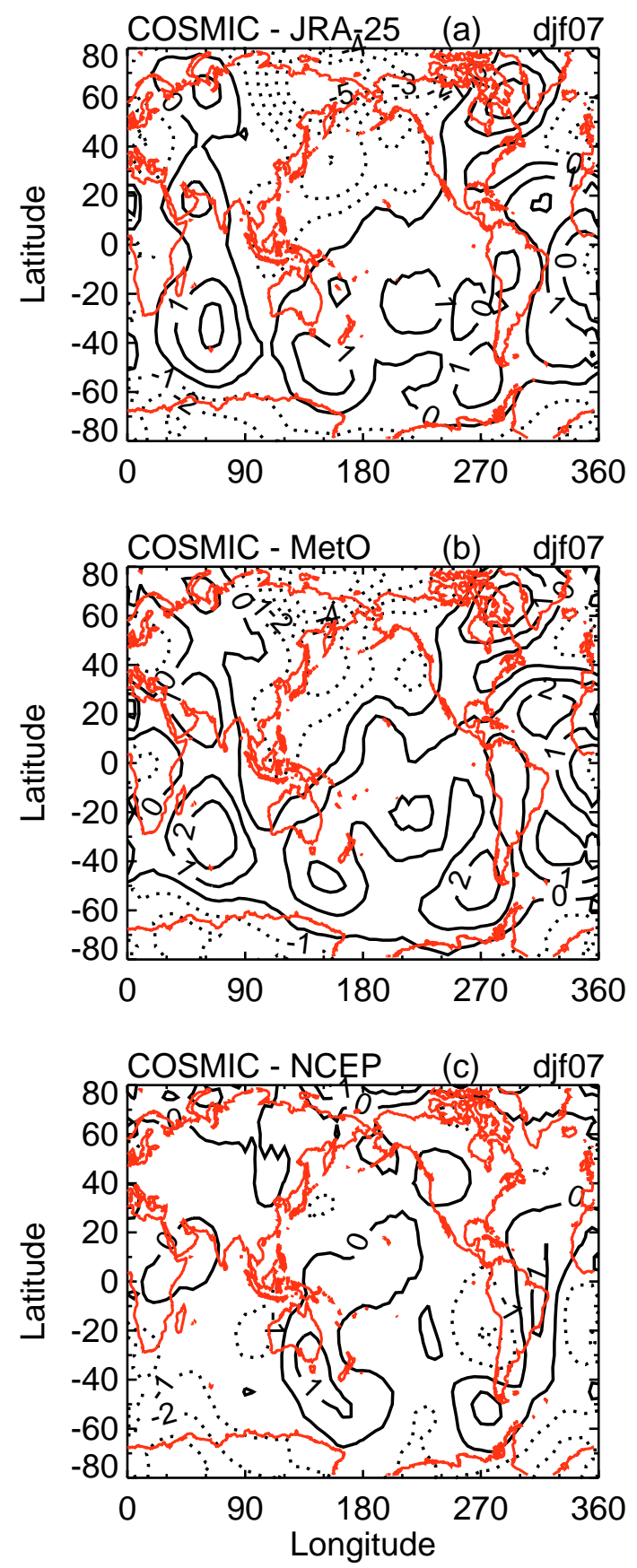

Fig. 7. Same as Fig. 6, but for Northern Hemisphere winter (December 2006, January, February 2007). The contour interval is $1 \mathrm{~K}$.

It is appropriate to show the statistical estimates of the bias between the COSMIC-NCEP, COSMIC-MetO and COSMIC-JRA-25 measurements obtained for different latitude sectors for summer and winter seasons at $100 \mathrm{hPa}$ and $50 \mathrm{hPa}$, and are shown in Tables 1 and 2. The tables depict that the winter differences are consistently larger than the summer for both pressure levels. The RMS deviations are in the range of $1.5-2.25 \mathrm{~K}$. The mean differences are larger 

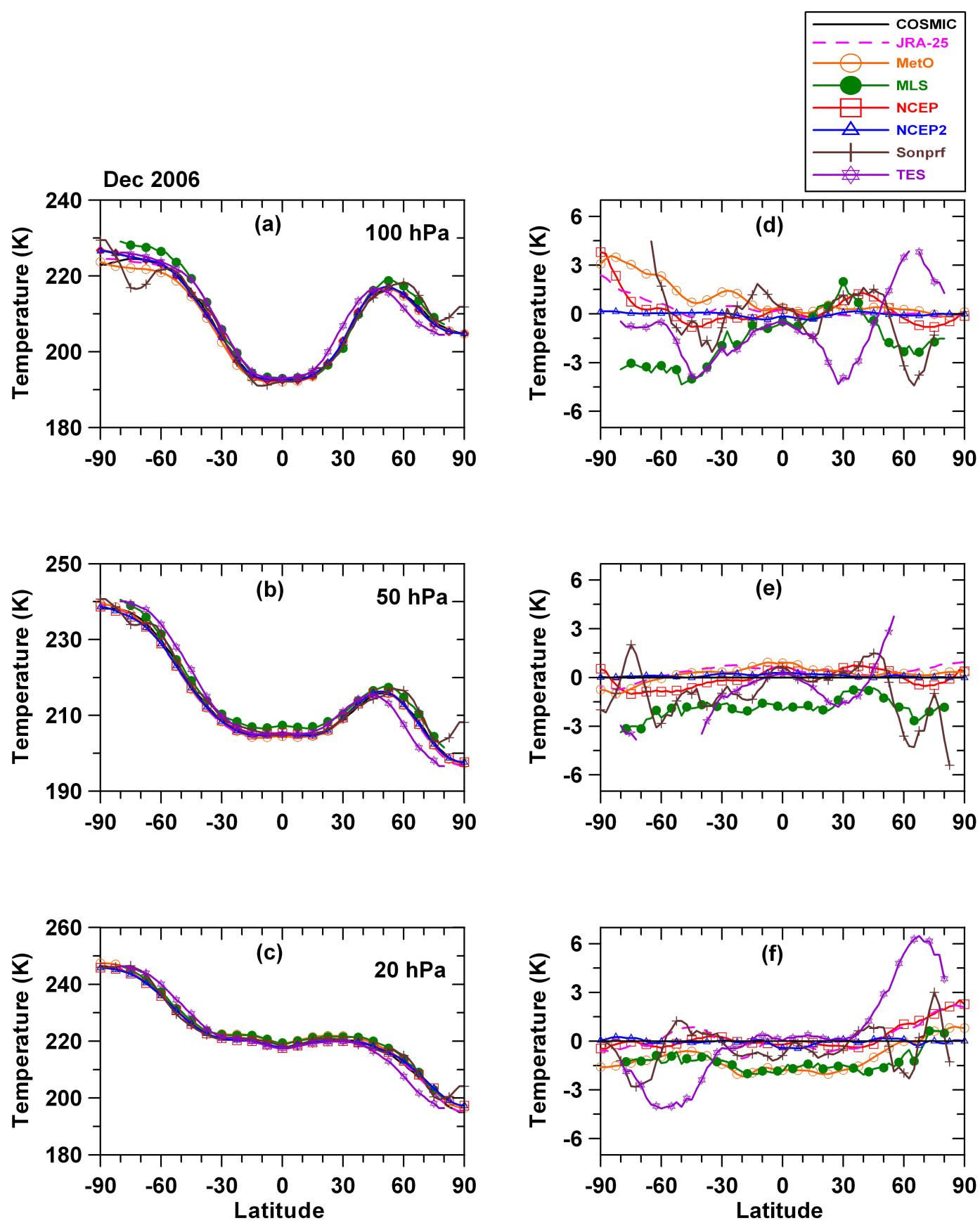

Fig. 8. Latitudinal distribution of mean zonal temperatures for (a) $100 \mathrm{hPa}$, (b) $50 \mathrm{hPa}$, and (c) $20 \mathrm{hPa}$. Various data sets shown in the figure correspond to December 2006. Distribution of differences with respect to COSMIC measurements and other data sets are given in the right panel (d-f).

at high latitudes in both summer and winter seasons for both pressure levels, especially for the MetO values.

\subsection{Latitudinal temperature variations at three different pressure levels}

The latitudinal temperature structure, at three different pressure levels in December 2006, obtained by the reanalysis and satellite measurements is shown in Fig. 8a-c. The three chosen pressure levels are $100 \mathrm{hPa}, 50 \mathrm{hPa}$ and $20 \mathrm{hPa}$. In the right panel (Fig. 8d-f) we show the differences with respect to the COSMIC measurements for the corresponding pressure levels. From Fig. 8a-c it is evident that the overall latitudinal structure is similar in each pressure level. Looking at the differences (Fig. 8d-f), large temperature differences 
are observed at $100 \mathrm{hPa}$ and less at $20 \mathrm{hPa}$ level. The TESAURA data exhibit larger temperatures (up to $\sim 5 \mathrm{~K}$ ) in the $\mathrm{SH}\left(50^{\circ} \mathrm{S}\right)$ region and they are smaller by $\sim 4 \mathrm{~K}$ in the $\mathrm{NH}$ $\left(70^{\circ} \mathrm{N}\right)$ region. The MLS-AURA measurements illustrate large spread for all the pressure levels and at almost all latitudes and basically they are warmer than the COSMIC temperatures for most of the sectors and pressure levels. The maximum difference observed in this case is $\sim 4 \mathrm{~K}$ in the upper troposphere and lower stratosphere. In the case of radiosonde temperatures at $100 \mathrm{hPa}$, they show larger temperatures (by $\sim 4 \mathrm{~K}$ ) in the Arctic region and smaller temperatures (by $\sim 4 \mathrm{~K}$ ) in the Antarctic region. In particular, the NCEP, NCEP 2, JRA-25 data agree better with the COSMIC measurements. The MetO data sets are consistent with COSMIC in the latitude range of $60^{\circ} \mathrm{S}-60^{\circ} \mathrm{N}$ and the bias increases to $2-3.5 \mathrm{~K}$ in the polar regions. Overall, it can be concluded that the temperature differences are comparatively smaller over the latitude sector $60^{\circ} \mathrm{N}-60^{\circ} \mathrm{S}$.

\section{Conclusions}

By April 2007 nearly half a million COSMIC radio occultations have been collected high-quality temperature profiles in the troposphere and lower stratosphere. Aiming a validation of the COSMIC temperature profiles, at first we have compared the COSMIC temperature profiles averaged for five different latitude bands with reanalysis data sets such as NCEP, JRA-25 and MetO. For the troposphere and stratosphere heights $(8-30 \mathrm{~km})$ considered in the present study, generally we found good agreement among various data sets. The mean differences averaged globally and over the height region between 8 and $30 \mathrm{~km}$ are estimated as $0.55 \pm 0.015 \mathrm{~K}$ and $0.65 \pm 0.02 \mathrm{~K}$, respectively.

The global temperature structures at $100 \mathrm{hPa}$ level revealed by the COSMIC and reanalyses, for the northern summer and winter seasons, again showed very good similarities in most of the latitude/longitude sectors. Further, we have given attention to note the difference between the COSMIC measurements and the reanalysis values obtained for the northern summer and winter seasons. For the summer season, the maximum differences are relatively smaller at about 0.75 $1.25 \mathrm{~K}$ for the $70^{\circ} \mathrm{S}-70^{\circ} \mathrm{N}$ latitude range and it increased to $1-2.5 \mathrm{~K}$ in the Polar region. Larger differences at the Polar latitudes are caused by the less RO coverage or lower vertical resolution of reanalysis values. Also the $\mathrm{SH}$ is less covered with regular meteorological observations. The MetO data show comparatively larger differences $(2.0-2.5 \mathrm{~K})$ in the equatorial latitudes.

During the northern winter season the bias is comparatively larger for the JRA-25 and MetO data sets. In the Arctic region the JRA-25 and MetO data sets show comparatively larger temperature values. However, the NCEP data show better resemblance with the COSMIC data. The observed differences can be attributed to the low vertical resolution of the reanalysis data or error introduced by the spherical symmetry assumption of COSMIC data retrieval. It is also probably affected by the stratospheric circulation in the $\mathrm{NH}$ characterized by strong major warming or strong planetary wave activity. Reanalysis data sets may not take into account such effects of rapid synoptic developments.

Comparison of latitudinal distribution of zonal mean temperatures performed for the $100 \mathrm{hPa}, 50 \mathrm{hPa}$, and $20 \mathrm{hPa}$ levels mostly show encouraging agreements. Noticeable differences of 3-4 K are mainly noted in the Polar regions. TESAURA and MLS-AURA measurements depict comparatively larger differences than other measurements. In the future we look forward to perform further investigations with additional COSMIC and other GPS RO measurements.

Acknowledgements. The authors would like to thank all the members of CDAAC team for providing the COSMIC data sets. The authors would also like to express their gratitude to the JRA-25 execution team of JMA and CRIEPI, the UK Met Office, the NOAA-CIRES Climate Diagnostic Centre, British Atmospheric Data Centre, etc. for the use of their respective data sets in this paper. The first author deeply appreciates and is grateful to the National Institute of Information and Communications Technology (NICT), for their financial support. J. H. Jiang thanks the support by Microwave Atmospheric Science Team at Jet Propulsion Laboratory, California Institute of Technology, under contract with NASA.

Edited by: W. Conant

\section{References}

Baray, J. L., Ancellet, G., Taupin, F. G., Bessafi, M., Baldy, S., and Keckhut, P.: Subtropical tropopause break as a possible stratospheric source of ozone in the tropical tropopause, J. Atmos. Solar-Terr. Phys., 60, 27-36, 1998.

Borsche, M., Kirchengast, G., and Foelsche, U.: Tropical tropopause climatology as observed with radio occultation measurements from CHAMP compared to ECMWF and NCEP, Geophys. Res. Lett., 34, L03702, doi:10:1029/2006GL027918, 2007.

Burris, J., Heaps, W., Gary, B., Hoegy, W., Lait, L., McGee, T., Gross, M., and Singh, U. N.: Lidar temperature measurements during the tropical ozone transport experiment (TOTE)/vortex ozone transport experiment (VOTE) mission, J. Geophys. Res., 103, 3505-3510, 1998.

Chanin, M. L. and Hauchecorne, A.: Lidar study of the structure and dynamics of the middle atmosphere, Indian J. Radio Space Phys., 20, 1-11, 1991.

Dewan, E. M., Grossbard, N., Quesada, A. F., and Good, R. E.: Spectral analysis of $10-\mathrm{m}$ resolution scalar velocity profiles in the stratosphere, Geophys. Res. Lett., 11, 80-83, 1984.

Eckermann, S. D., Hirota, I., and Hocking, W. K.: Gravity wave and equatorial wave morphology of the stratosphere derived from long-term rocket sounding. Q. J. Roy. Meteorol. Soc., 121, 149186, 1995.

Gobiet, A., Foelsche, U., Steiner, A. K., Borsche, M., Kirchengast G., and Wickert, J.: Climatological validation of stratospheric temperatures in ECMWF operational analyses with CHAMP 
radio occultation data, Geophys. Res. Lett., 32, L12806, doi:10.1029/2005GL022617, 2005.

Hajj, G. A., Kursinski, E. R., Romans, L. J., Betiger, W. I., and Leroy, S. S.: A technical description of atmospheric sounding by GPS occultation, J. Atmos. Solar-Terr. Phys., 64, 451-469, 2002.

Hajj, G. A., Ao, C. O., Iijima, B. A., Juang, D., Kursinski, E. R., Mannucci, A. J., Meehan, T. K., Romans, L. J., de le Torre Juarez, M., and Yunck, T. P.: CHAMP and SAC-C atmospheric occultation results and intercomparisons, J. Geophys. Res., 109, D06109, doi:10.1029/2003JD003909, 2004.

Hamilton, K.: Climatological statistics of stratospheric inertia gravity waves deduced from historical rocketsonde wind and temperature data, J. Geophys. Res., 96, 831-839, 1991.

Hauchecorne, A. and Chanin, M. L.: Density and temperature profiles obtained by lidar between 35 and $70 \mathrm{~km}$, Geophys. Res. Lett., 8, 565-568, 1980.

Hertzog, A., Basdevant, C., Vial, F., and Mechoso, C. R.: Some results on the accuracy of stratospheric analyses in the Northern Hemisphere inferred from long-duration balloon flights, Q. J. Roy. Meteorol. Soc., 130, 607-626, 2003.

Hoinka, K. P.: Statistics of the global tropopause pressure, Mon. Weather. Rev., 126, 3303-3325, 1998.

Holton, J. R., Haynes, P. H., McIntyre, M. E., Douglass, A. R., Rood, R. B., and Pfister, L.: Stratosphere-troposphere exchange, Rev. Geophys., 33, 403-439, 1995.

Jiang, J. H., Wang, D. Y., Romans, L. J., Ao, C. O., Schwartz, M. J., Stiller, G. P., von Clarmann, T., Puertas, M. L., Funke, B., Lopez, S. G., Glatthor, N., Grabowski, U., Höpfner, M. Kellmann, S., Kiefer, M., Linden, A., Mengistu-Tsidu, G., Milz, M., Steck, T., and Fischer, H.: Comparison of GPS/SAC-C and MIPAS/ ENVISAT Temperature Profiles and Its Possible Implementation for EOS MLS Observations, in: CHAMP Mission Results for Gravity and, Magnetic Field Mapping, and GPS Atmospheric sounding, edited by: Reigber, C., Luehr, H., Schwintzer, P., and Wickert, J., Springer-Verlag, Berline/Heidelberg/New York, pp. 573-578, 2004

Kalnay, E., Kanamitsu, M., Kistler, R., et al.: The NCEP/NCAR 40-year reanalysis project, B. Am. Meteorol. Soc., 77, 437-471, 1996.

Kishore, P., Namboothiri, S. P., Igarashi, K., Jiang, J. H., Ao, C. O., and Romans, L. J.: Climatological characteristics of the tropopause parameters derived from GPS/CHAMP and GPS/SAC-C measurements, J. Geophys. Res., 111, D20110, doi:10.1029/2005JD006827, 2006.

Kistler, R., Kalnay, E., Collins, W., et al.: The NCEP-NCAR reanalysis: Monthly means CD-ROM and documentation, B. Am. Meteorol. Soc., 82, 247-267, 2001.

Kitamura, Y. and Hirota, I.: Small-scale disturbances in the lower stratosphere revealed by daily rawinsonde observations, J. Meteorol. Soc. Japan, 67, 817-831, 1989.

Knudsen, B. M., Pommereau, J. P., Garnier, A., Nunes-Pinharandra. M., Denis, L., Newman, P., Letrenne, G., and Durand, M.: Accuracy of analyzed stratospheric temperatures in the winter arctic vortex from infra red montgolfer long duration balloon flights, Part II: Results, J. Geophys. Res., 107, D20, doi:10.1029/2001JD001329, 2002.

Kursinski, E. R., Hajj, G. A., Hardy, K. R., Schofield, J. T., and Linfield, R.: Observing Earth's atmosphere with radio occultation measurements using the Global Positioning System, J. Geophys.
Res., 102, 23429-23465, 1997.

LeBlanc, L. S., Mcdermid, L. S., Hauchecorne, A., and Keckhut, P.: Evaluation and optimization of lidar temperature analysis algorithms using simulated lidar data, J. Geophys. Res., 103, 61776187, 1998.

Lorenc, A. C., Ballard, S. P., Bell, R. S., et al.: The Met Office global 3-dimensional variational data assimilation scheme, Q. J. Roy. Meteorol. Soc., 126, 2991-3012, 2000.

Marquardt, C., Schoellhammer, K., Beyerle, G., Schmidt, T., Wickert, J., and Reigber, C.: Validation and data quality of CHAMP radio occultation data, in: First CHAMP Mission Results for Gravity, Magnetic and Atmospheric Studies, pp. 384 396, Springer, New York, 2003.

Newell, R. E., Kidson, J. W., Vincent, D. G., and Boer, G. J.: The general circulation of the tropical atmosphere and interactions with extra tropical latitudes, The MIT Press, pp. 258, 1972.

Newell, R. E. and Gould-Stewart, S.: A stratospheric fountain?, J. Atmos. Sci., 38, 2789-2797, 1981.

Nishida, M., Shimizu, A., Tsuda, T., Rocken, R., and Ware, R. H.: Seasonal and longitudinal variations in the tropical tropopause observed with the GPS occultation technique (GPS/MET), J. Meteor. Soc. Jpn., 78, 691-700, 2000.

Onogi, K., Koide, H., Sakamoto, M., Kobayashi, S., Tsutsui, J., Hatsushika, H., Matsumoto, T., Yamazaki, N., Kamahori, H., Takahashi, K., Kato, K., Ose, T., Kadokura, S., and Wada, K.: JRA-25; Japanese 25-year Reanalysis progress and status, Q. J. Roy. Meteorol. Soc., 131, 3259-3268, 2005.

Onogi, K., Tsutsui, J., Koide, H., Sakamoto, M., Kobayashi, S., Hatsushika, H., Matsumoto, T., Yamazaki, N., Kamahori, H., Takahashi, K., Kadokura, S., Wada, K., Kato, K., Oyama, R., Ose, T., Mannoji, N., and Taira, R.: The JRA-25 Reanalysis, Q. J. Roy. Meteorol. Soc., 85, 369-432, 2007.

Pommereau, J. P., Garnier, A., Knudsen, B. M., et al.: Accuracy of analyzed stratospheric temperatures in the winter arctic vortex from infra red montgolfer long duration balloon flights Part I: Measurements, J. Geophys. Res., 107, D20, doi:10.1029/2001JD001379, 2002.

Randel, W. J., Wu, F., and Rios, W. R.: Thermal variability of the tropical tropopause region derived from GPS/MET observations, J. Geophys. Res., 108, 4024, doi:10.1029/2002JD002595, 2003.

Ringer, M. A. and Healy, S. B.: Monitoring twenty-first century climate using GPS radio occultation bending angles, Geophys. Res. Lett., 35, L05708, doi:10.1029/2007GL032462, 2008.

Rocken, C., Anthes, R., Exner, M., et al.: Analysis and validation of GPS/MET data in the neutral atmosphere, J. Geophys. Res., 102, D25, 29849-29866, 1997.

Rocken, C., Kuo, Y. H., Schreiner, W., Hunt, D., Sokolovskiy, S., and McCormick, C.: COSMIC System Description, Terr. Atmos. Oceanic Sci., 11, 21-52, 2000.

Schmidt, T., Wickert, J., Beyerle, G., and Reigber, C.: Tropical tropopause parameters derived from GPS radio occultation measurements with CHAMP, J. Geophys. Res., 109, D13105, doi:10.1029/2004JD004566, 2004.

Schreiner, W., Rocken, C., Sokolovskiy, S., Syndergaard, S., and Hunt, D.: Estimates of the precision of GPS radio occultations from the COSMIC/FORMOSAT-3 mission, Geophys. Res. Lett., 34, L04808, doi:10.1029/2006GL027557, 2007.

Sivakumar, V., Rao, P. B., and Krishnaiah, M.: Lidar measurements of stratosphere-mesosphere thermal structure over a low latitude: 
Comparison with satellite data and models, J. Geophys. Res., 108, D11, doi:10.1029/2002JD003029, 2003.

Steinbrecht, W., Claude, H., Kohler, U., and Hoinka, K. P.: Correction between tropopause height and total ozone: Implication for long-term changes, J. Geophys. Res., 103, 19183-19192, 1998.

Steiner, A. K. and Kirchengast, G.: Gravity wave spectra from GPS/MET occultation observations, J. Atmos. Oceanic Tech., 17, 495-503, 2000.

Swinbank, R. and O'Neill, A.: A stratosphere-troposphere data assimilation system, Mon. Weather. Rev., 122, 686-702, 1994.

Syndergaard, S.: On the ionosphere calibration in GPS radio occultation measurements, Radio. Sci., 35, 865-884, 2000.

Tsuda, T., VanZandt, T. E., Mizumoto, M., Kato, S., and Fukao, S.: Spectral analysis of temperature and Brunt-Vaisala frequency fluctuations observed by radiosondes, J. Geophys. Res., 96, 17265-17278, 1991.
Wang, D. Y., Stiller, G. P., Clarmann, T. V., Fischer, H., LopezPuertas, M., Funke, B., Glatthor, N., Grabowski, U., Hopfner, M., Kellmann, S., Kiefer, M., Linden, A., Tsidu, G. M., Milz, M., Steck, T., Jiang, J. H., Ao, C. O., Manney, G., Hocke, K., Wu, D. L., Romans, L. J., Wickert, J., and Schmidt, T.: Cross validation of MIPAS/ENVISAT and GPS/CHAMP temperature profiles, J. Geophys. Res., 109, D19311, doi:10.1029/2004JD004963, 2004.

Whiteway, J. A. and Carswell, A. I.: Rayleigh lidar observations of thermal structure and gravity wave activity in the high Arctic during a stratospheric warming, J. Atmos. Sci., 51, 3122-3136, 1994.

Wickert, J., Reigber, C., Beyerle, G., et al.: Atmosphere sounding by GPS radio occultation: First results from CHAMP, Geophys. Res. Lett., 28, 3263-3266, 2001.

Wilson, R., Hauchecorne, A., and Chanin, M. L.: Gravity wave spectra in the middle atmosphere as observed by Rayleigh lidar, J. Geophys. Res., 96, 5153-5167, 1991. 